\title{
LETTERS \\ Innovative Approaches to Studying Health Outcomes in Rare Diseases
}

\author{
William R. Phillips, MD, MPH \\ Department of Family Medicine, School of Medicine, University of Washington, Seattle, USA.
}

$\mathrm{J}$ Gen Intern Med 30(1):8

DOI: $10.1007 / \mathrm{s} 11606-014-3068-6$

(c) Society of General Internal Medicine 2014

$\mathrm{T}$ o the Editor: As emphasized by the valuable Journal or General Internal Medicine supplement, rare diseases are important (Volume 29, Issue 3 Supplement, August 2014). ${ }^{1,2}$ They constitute heavy burdens of suffering for patients, growing problems for our health care system and important areas for scientific research. The care of patients with rare diseases is also an important aspect of primary care practice. ${ }^{3}$ Primary care physicians are specialists in the care of common problems, but common patients sometimes have rare diseases. Primary care includes the responsibility for recognizing such problems and managing such patients. Practice-based research documents that primary care physicians care for patients with a wide variety of rare disorders across the spectrum of patient age and sex, organ system involved, and medical specialty area. ${ }^{4}$ In the majority of cases, primary care physicians identify the rare problem, diagnose the disorder, and provide acute and continuing care, even for life-threatening conditions. ${ }^{4}$ Patients with rare diseases have common needs, too, and primary care physicians manage most of that continuing care. ${ }^{5}$ For the practicing primary care clinician, this responsibility is much more than a collection of rare diseases or memorable cases. It is the care of exceptional patients with special needs and it offers professional challenges and opportunities for personal growth.

Conflict of Interest: The author declares that he does not have a conflict of interest.

Corresponding Author: William R. Phillips, MD, MPH; Department of Family Medicine, School of MedicineUniversity of Washington, Box 356390, Seattle 98195, USA (e-mail: wphllps@uw.edu).

\section{REFERENCES}

1. Kesselheim AS, Gagne JJ. Introduction to a supplement on innovative approaches to studying health outcomes in rare diseases. J Gen Intern Med 2014;29(Suppl 3):S709-11.

2. Smith SR. Preface to the AHRQ supplement. J Gen Intern Med. 2014;29 (Suppl 3):S712-3.

3. Knight AW, Senior TP. The common problem of rare disease in general practice. Med J Aust. 2006;185:82-83.

4. Phillips WR. Zebras on the commons: rare conditions in family practice. J Am Board Fam Pract. 2004; 17:283-6.

5. Senior TP, Knight AW. Rare diseases: a role for primary care. Lancet. 2008;13;372(9642). 